\title{
COMPOSITION AND STABILIZATION OF SHARK LIVER OIL EXTRACTS OF SELECTED SHARK SPECIES
}

by

\section{CHAMILA VINODANEE LIYANAGE}

B. Sc. \{University of Peradeniya, Sri Lanka\}

M. Sc. (Food Science \& Technology) \{University of Sri Jayawardanepura, Sri Lanka\}

Thesis submitted to the University of Sri Jayawardanepura, Sri Lanka for the award of the Degree of Master of Philosophy in Chemistry on $11^{\text {th }}$ November 1999. 


\section{DECLARATION}

"The work described in this thesis was carried out by me under the supervision of Professor A. Bamunuarachchi (Department of Chemistry, University of Sri Jayawardanepura, Nugegoda, Sri Lanka) and Dr. W. M. K. Perera (Senior Research Officer, Institute of Post Harvest Technology, National Aquatic Resources Research and Development Agency, Colombo 15, Sri Lanka) and the report on this has not been submitted to any university for another degree".

Date : 1999-11-11

$$
\text { dyfangl }
$$

Chamila Vinodanee Liyanage 


\section{DECLARATION OF THE SUPERVISORS}

"We certify that the above statement made by the candidate is true and that this thesis is suitable for submission to the University for the purpose of evaluation"

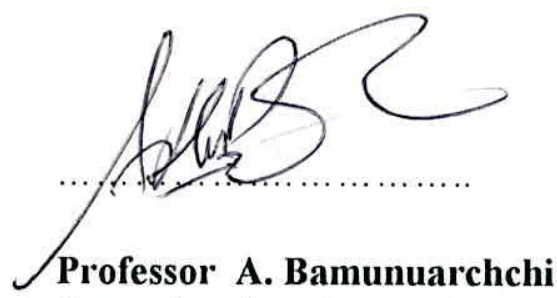

Supervisor / Professor of Applied Chemistry Department of Chemistry University of Sri Jayawardanepura Nugegoda

Sri Lanka.

Dr. W. M. K. Perera

Supervisor / Senior Research Officer Institute of Post Harvest Technology National Aquatic Resources Research \& Development Agency (NARA)

Crow Island, Colombo 15 Sri Lanka. 


\section{CONTENTS}

Page No

I. CONTENTS

II. LIST OF TABLES vii

III. LIST OF FIGURES viii

IV. LIST OF PLATES xii

V. ACKNOWLEDGMENTS xiii

VI. ABSTRACT $\mathrm{xV}$

1. INTRODUCTION 1

2. LITERATURE REVIEW 6

2.1 Nutritive value of fish 6

2.1.1 Fish oil 7

2.1.2 Shark liver oil 9

2.2 Fish production in Sri Lanka 11

2.2.1 Shark production 11

2.3 Composition of fish oil 13

2.3.1 Composition of shark liver oil 14

2.4 Handling and preservation of shark livers 15

2.5 Extraction of liver oil 18

2.6 Lipid oxidation $\quad 21$

2.6.1 Mechanism of lipid oxidation 24

2.6.2 Use of antioxidants $\quad 27$

2.6.3 Synthetic antioxidants 28

2.6.3.1 Butylatedhydroxy anisole (BHA) and butylatedhydroxy toluene (BHT) 29

2.6.3.2 Tertiary butylehydro quinone (TBHQ) 30

2.6.3.3 Gallate esters 31 
2.6.4 Natural antioxidants

2.6.4.1 Rosemary

2.6.4.2 Soy bean 36

2.6.4.3 Peanut 36

2.6.4.4 Cotton seed 37

2.6.4.5 Olive 37

2.6.4.6 Mustard and Rape seed 38

2.6.4.7 Corn 38

2.6.4.8 Flaxseed 39

2.6.4.9 Sesame 39

2.6.4.10 Rice 40

2.6.4.11 Turmeric 40

2.6.5 Estimation of antioxidant activity

3.1 Determination of proximate composition of shark liver

3.1.1 Determination of moisture

3.1.1.1 Materials

3.1.1.2 Method

3.1.2 Determination of ash

3.1.2.1 Materials

3.1.2.2 Method

3.1.3 Determination of oil content

3.1.3.1 Materials

3.1.3.2 Method

3.1.4 Determination of crude protein 46

3.1.4.1 Materials 46

3.1.4.2 Method 47

3.2 Evaluation of liver quality at the landing site, in ice $\left(0^{\circ} \mathrm{C}\right)$ and frozen $\left(-18^{\circ} \mathrm{C}\right)$ storage $\quad 49$

3.2.1 Evaluation of quality of liver at the landing site 49

3.2.1.1 Sensory evaluation of shark livers 49

3.2.1.1.1 Materials

49 
3.2.1.1.2 Method

3.2.1.2 Determination of $\mathrm{pH} \quad 49$

3.2.1.2.1 Materials 49

3.2.1.2.2 Method 50

3.2.1.3 Determination of total volatile nitrogen 50

3.2.1.3.1 Materials 50

3.2.1.3.2 Method 50

3.2.1.4 Determination of quality of liver oil 51

3.2.1.5 Determination of peroxide value of liver oil 52

3.2.1.5.1 Materials 52

3.2.1.5.2 Method 52

3.2.1.6 Determination of free fatty acid value of liver oil

3.2.1.6.1 Materials 53

3.2.1.6.2 Method 53

3.2.2 Assessment of quality changes in shark livers in ice storage 54

3.2.2.1 Materials 54

3.2.2.2 Method 54

3.2.3 Assessment of quality changes in shark livers in frozen storage 55

3.2.3.1 Materials 55

3.2.3.2 Method 55

3.3 Determination of fatty acid composition 55

3.3.1 Material 55

3.3.2 Method 56

3.4 Seasonal variation of oil content of shark livers 58

3.4.1 Materials 58

3.4.2 Method 58

3.5 Extraction techniques and quality determination of liver oil 58

3.5.1 Wet rendering method 58

3.5.1.1 Materials 58

3.5.1.2 Method 59 
3.5.2 Steam rendering method

3.5.2.1 Materials

3.5.2.2 Method

3.5.3 Chloroform-methanol extraction method 60

3.5.3.1 Materials 60

3.5.3.2 Method 60

3.5.4 Acid silage method 60

3.5.4.1 Materials 60

3.5.4.2 Method 61

3.5.5 Alkali digestion method 61

3.5.5.1 Materials 61

3.5.5.2 Method 61

3.5.6 Incubation method 62

3.5.6.1 Materials 62

3.5.6.2 Method 62

3.5.7 Determination of quality of extracted liver oil 62

3.5.7.1 Determination of anisidine value 63

3.5.7.1.1 Materials 63

3.5.7.1.2 Method 63

3.5.7.2 Determination of total oxidation value 64

3.6 Assessment of suitable preservatives during oil extraction 64

3.6.1 Preparation of fruit extract 64

3.6.1.1 Materials 64

3.6.1.2 Method 65

3.6.2 Ensilage method 65

3.6.2.1 Materials 65

3.6.2.2 Method 65

3.6.3 Steam rendering process 66

3.6.3.1 Materials 66

3.6.3.2 Method 66

3.7 Effectiveness of antioxidants on liver oil oxidation 67

$\begin{array}{lll}\text { 3.7.1 Preparation of plant extracts } & 67\end{array}$ 
3.7.1.1 Materials

3.7.1.2 Method

3.7.2 Preparation of shark liver oil 68

3.7.2.1 Materials 68

3.7.2.2 Method 68

3.7.3 Identification of suitable oil preservative 68

3.7.3.1 Materials 68

3.7.3.2 Method 69

3.7.4 Assessment of optimum requirement of selected preservatives 69

3.7.4.1 Materials 69

$\begin{array}{ll}3.7 .4 .2 \text { Method } & 70\end{array}$

3.7.5 Determination of iodine value 70

$\begin{array}{lll}3.7 .5 .1 & \text { Materials } & 70\end{array}$

3.7.5.2 Method 71

3.7.6 Determination of 2-thiobarbaturic acid value 72

3.7.6.1 Materials $\quad 72$

3.7.6.2 Method 72

$\begin{array}{lll}3.8 & \text { Statistical analysis } & 73\end{array}$

4 RESULTS AND DISCUSSION $\quad 74$

4.1 Proximate composition of shark livers of different shark species $\quad 74$

4.1.1 Moisture content 74

4.1.2 Ash content 76

4.1.3 Protein content 76

4.1.4 Lipid content 77

4.2 Evaluation of liver and liver oil quality at the landing site and during storage $\quad 82$

4.2.1 Evaluation of liver quality at the landing site 82

4.2.2 Quality changes of shark livers during storage 90

4.2.2.1 Evaluation of quality of liver and liver oil during ice $\left(0^{\circ} \mathrm{C}\right)$ storage $\quad 90$ 
4.2.2.2 Evaluation of liver and liver oil quality during frozen $\left(-18^{\circ} \mathrm{C}\right)$ storage $\quad 96$

4.3 Fatty acid composition of selected shark species 102

4.4 Effect of seasonal variation on liver oil content of Silky (Carcharhinus falciformis), Hammerhead (Sphyrna lewini) and

Oceanic white tip sharks (Carcharhinus longimanus)

4.5 Quality of shark liver oil extracted by different methods 117

4.6 Effect of preservatives on quality of liver oil during extraction 125

4.6.1 Extraction of oil by ensilage method 125

4.6.2 Extraction of oil by steam rendering method $\quad 130$

4.7 Effectiveness of antioxidants on prevention of oxidation of liver 137 oil

4.7.1 Identification of suitable oil preservatives 137

4.7.2 Optimum requirement of selected preservatives $\quad 143$

5 CONCLUSIONS $\quad 150$

$\begin{array}{lr}\text { LITERATURE CITED } & 154\end{array}$

$\begin{array}{ll}\text { PLATES } & 165\end{array}$

LIST OF RESEARCH PUBLICATIONS AND COMMUNICATIONS

$\begin{array}{lr}\text { FROM THE STUDY } & 169\end{array}$ 


\section{LIST OF TABLES}

Page No

Table 4.1.1 Proximate composition of livers of different shark species collected from West coast of Sri Lanka

Table 4.2.1 Organoleptic score card used for evaluation of shark livers

Table 4.2.2 Correlation coefficient of organoleptic score against total volatile nitrogen value, $\mathrm{pH}$ value, free fatty acid $\%$ and peroxide value of shark livers and liver oil

Table 4.2.2.1 Results of the bio-chemical variation of shark livers and oil during ice storage

Table 4.2.2.2. Results of the bio-chemical variation of shark livers and oil during frozen storage

Table 4.3 Composition of major fatty acids in oil of different shark species

Table 4.5.1 Analysis of crude silky shark liver oil extracted from different techniques

Table 4.7.1 Variation of free fatty acid value with storage time

Table 4.7.2 Variation of peroxide value with storage time

Table 4.7.3 Variation of para anisidine value with storage time

Table 4.7.4 Variation of iodine value with storage time 


\section{LIST OF FIGURES}

Page No

Figure 2.1 The free radical chain mechanism of autoxidation

Figure 2.2 Formation of lipid peroxi radicals

Figure 2.3 A generalized scheme for autoxidation of lipids

$\begin{array}{lll}\text { Figure 2.4 Structure of BHA \& BHT } & 30\end{array}$

$\begin{array}{lll}\text { Figure 2.5 Structure of TBHQ } & 31\end{array}$

$\begin{array}{lll}\text { Figure 2.6 Structure of PG } & 32\end{array}$

$\begin{array}{lll}\text { Figure } 2.7 & \text { Structure of curcumin } & 40\end{array}$

$\begin{array}{lll}\text { Figure 2.8 } & \text { Structure of demethoxy curcumin } & 40\end{array}$

$\begin{array}{lll}\text { Figure } 2.9 & \text { Structure of bis-demethoxi curcumin } & 41\end{array}$

Figure 4.1.1 Liver oil contents of some common shark species in Sri

Lanka

Figure 4.2.1 Liver quality of silky (Carcharhinus falciformis) sharks at Negambo and Beruwala landing sites

Figure 4.2.2 Variation of liver quality (freshness) of sharks with $\mathrm{pH}$ value, total volatile content, free fatty acid $\%$ and peroxide values

Figure 4.2.2.1 Variation of $\mathrm{pH}$ value of shark liver during ice $\left(0^{\circ} \mathrm{C}\right)$ storage

Figure 4.2.2.2 Variation of total volatile nitrogen content of shark liver during ice $\left(0^{\circ} \mathrm{C}\right)$ storage 
Figure 4.2.2.3 Variation of free fatty acid value of shark liver during ice

$\left(0^{\circ} \mathrm{C}\right)$ storage

Figure 4.2.2.4 Variation of peroxide value of shark liver during ice $\left(0^{\circ} \mathrm{C}\right)$

storage

Figure 4.2.2.5 Variation of $\mathrm{pH}$ value of shark liver during frozen $\left(-18^{\circ} \mathrm{C}\right)$

storage

Figure 4.2.2.6 Variation of total volatile nitrogen of shark livers during

frozen $\left(-18^{\circ} \mathrm{C}\right)$ storage

98

Figure 4.2.2.7 Variation of free fatty acid of shark liver during frozen

$\left(-18^{\circ} \mathrm{C}\right)$ storage

Figure 4.2.2.8 Variation of peroxide value of shark liver during frozen

$\left(-18^{\circ} \mathrm{C}\right)$ storage

Figure 4.3.1 Saturated fatty acids contents of liver oil of three different shark species

Figure 4.3.2 Percentages of mono unsaturated fatty acids of liver oil of three different shark species

Figure 4.3.3 Percentages of poly unsaturated fatty acids of liver oil of three different shark species

Figure 4.3.4 Percentages of n-3 poly unsaturated fatty acids of liver oil of three different shark species

Figure 4.4.1 Seasonal variation of liver oil content of male and female silky, hammerhead and oceanic white tip sharks

Figure 4.5.1 Oil yields of different extraction methods

Figure 4.5.2 Free fatty acid values of oils from different extraction methods

Figure 4.5.3 Peroxide values of oils from different extraction methods 
Figure 4.5.4 Thiobarbaturic acid values of oils from different extraction methods

Figure 4.6.1.1 Yield of oil extracted by different treatments of silage method

Figure 4.6.1.2 Free fatty acid \% of oil extracted by different treatments of silage method

Figure 4.6.1.3 Peroxide value of oil extracted by different treatments of silage method

Figure 4.6.1.4 Para anisidine value of oil extracted by different treatments of silage method

Figure 4.6.1.5 Total oxidation value of oil extracted by different treatments of silage method

Figure 4.6.2.1 Yield of oil extracted by steam rendering method using different treatments

Figure 4.6.2.2 Free fatty acid \% of oil extracted by steam rendering method using different treatments

Figure 4.6.2.3 Peroxide value of oil extracted by steam rendering method using different treatments

Figure 4.6.2.4 Para anisidine value of oil extracted by steam rendering method using different treatments

Figure 4.6.2.5 Total oxidation value of oil extracted by steam rendering method using different treatments

Figure 4.7.1 The initial and final free fatty acid content of liver oil treated with five different antioxidants

Figure 4.7.2 The initial and final peroxide value of liver oil treated with five different antioxidants 
Figure 4.7.3 The initial and final para anisidine value of liver oil treated with five different antioxidants

Figure 4.7.4 The initial and final iodine value of liver oil treated with five different antioxidants

Figure 4.7.5 The effect of antioxidants; BHT, ascorbic acid, tamarind fruit extract, tamarind seed extract and turmeric extract on oxidation rancidity of shark liver oil

Figure 4.7.6 Oxidation of shark liver oil treated with ethanolic extracts of turmeric \& BHT during storage as measured by peroxide value

Figure 4.7.7 Hydrolysis of shark liver oil treated with ethanolic extracts of turmeric \& BHT during storage as measured by free fatty acid

Figure 4.7.8 Oxidation of shark liver oil treated with ethanolic extracts of turmeric \& BHT during storage as measured by thio barbaturic acid value 


\section{LIST OF PLATES}

Page No

Plate - 01 Beruwala and Negombo fish landing sites in West coast of Sri Lanka 163

Plate-02 Selected shark species 164

Plate - 03 Natural antioxidants 166 


\section{ACKNOWLEDGEMENT}

I would like to express my sincere gratitude to my supervisors, Professor A. Bamunuarachchi and Dr. W. M. K. Perera for their valuable guidance extended and constructive criticism throughout my study and also critical reading of the manuscript.

I am very grateful to Dr. M. U. Jayasekara (former Director General, NARA), Dr. V. K. Graffham (former Head, IPHT, NARA) for their valuable guidance and making necessary arrangements to obtain financial support from the European Economic Community (EEC) under the project on Science and Technology for Development Phase III (STD3) "Improved utilization of low value fish species", grant no TS3* CT93 - 0207 through Food and Agriculture Organization and NARA.

My special thanks to Professor P. W. Epasinghe (Chairman, NARA); Dr. D. S. Jayakody, (Director General, NARA); Dr. J. M. P. K. Jayasinghe (Head, IPHT, NARA), Professor T. S. G. Fonseka (former Head, IPHT, NARA) and Professor W. S. Fernando ( Dean, Faculty of Applied Science, University of Sri Jayawardanepura) for their encouragement and co-operation given to me through out the study period.

My sincere thanks also given to Mr. R. Edirisinghe (Research Officer), Mr. S. Jayasooriya, Mrs. K. Hettiarachchci, Mrs. J. M. Chandrika, Mrs. R. Samaradivakara, Mr. C. Galappaththi,, Mr. G. Wijerathna, Miss. M. Paththapperuma, Mrs. U. K. Kusumalatha and Mr. K. Jayasena and other staff members of the IPHT, for their 
assistance in collecting and analyzing the samples in an efficient manner and support extended to complete this study successfully.

I am deeply indebted to Mr. David James (Senior Fishery Industry Officer, FAO); Dr. Peter Ben Embarek (Co-ordinator, STD3 Project) and Professor H. H. Huss (Research Co-ordinator, EEC) for their co-operation extended to complete the program successfully and providing opportunities to participate at International Conferences held in Sri Lanka, Philippines and China.

I greatly appreciate the support of Mr. S. Amarasekara (Indo Pacific Tuna Programme), Mr. D Amarasooriya (Research Officer, NARA) and Mr. A. Gunarathne (Information Officer, NARA) to prepare this thesis in good manner.

I would also like to thank Mr. G. Jayasinghe and Mr. S. Mohottala (Scientific Officer, CISIR) for assistance provided me with their comments.

Finally my special thanks to my dearest Jagath and parents, without their blessing, support and constant encouragement, I would never have completed this study successfully and I get this opportunity to dedicate the thesis to my loving daughter Yomalka. 


\title{
ABSTRACT \\ COMPOSITION AND STABILIZATION OF SHARK LIVER OIL EXTRACTS OF SELECTED SHARK SPECIES.
}

\author{
By \\ Chamila Vinodanee Liyanage
}

\begin{abstract}
In the recent years, scientists have given more emphasis on the use and stability of fish lipid in the food industry as it consists of unsaturated fatty acids with distinct health and pharmaceutical value. This thesis presents the results of a series of experiments carried out on shark liver oil with regard to its composition, extraction methods, seasonal variations of oil content and stabilization using natural antioxidants.

Liver samples of fifteen shark species landed in the West coast of Sri Lanka were analyzed for proximate composition. Silky shark (Carcharhinus falciformis), Hammerhead shark (Sphyrna lewini) and Oceanic white tip shark (Carcharhinus longimanus) were selected for further studies as they have been identified as the predominant species with comparatively high liver oil content.

As the quality of raw livers has an affect on the oil quality, selection of fresh livers for oil extraction is very important. Organoleptic score card developed in the present study categorized $4.3 \%$ of the livers as best in quality while $30.4,56.5$ and 8.7 percentages as good, medium and poor in quality respectively at landing sites of Negombo and
\end{abstract}


Beruwala. Icing $\left(0^{\circ} \mathrm{C}\right)$ and good handling practices on board would help to maintain the freshness of livers for more than 15 days.

Fatty acid composition of liver oil of three species were determined. Palmitic acid (C16:0; 22-26\%) was dominant followed by oleic $(\mathrm{C} 18: 1 ; 13-23 \%)$ out of twenty fatty acids identified. Significantly $(\mathrm{p}<0.05)$ highest $\mathrm{n}-3$ poly unsaturated fatty acids(PUFAs) recorded by silky shark (Carcharhinus falciformis) (27.4\%) followed by hammerhead (Sphyrna lewini) (24.6\%) and oceanic white tip (Carcharhinus longimanus) (20.2\%) sharks. The contribution of eicosapentaenoic and docosapentaenoic acids for the total n3 PUFAs by the three shark species was very high. Oceanic white tip (Carcharhinus longimanus) contributed highest value (94\%) while hammerhead (Spyrina lewini) and silky shark (Carcharhinus falciformis) contributed (85\%) and (77\%) respectively. The ratio of $n-3 / n-6$ was highest (6) in oceanic white tip shark (Carcharhinus longimanus) liver oil. The variation pattern of liver oil content of silky (Carcharhinus falciformis) and hammerhead (Sphyrna lewini) shark species showed more over similar and high values in December and law values in March - April. But, oceanic white tip shark (Carcharhinus longimanus) showed peak values in October. Results of this study revealed that liver oil content varies with the species, season and gender.

Influence of extraction methods ie., steam rendering, wet rendering, incubation, alkali digestion and acid silage on the quality and yield of shark liver oil was determined. Results suggested that extraction of oil using steam rendering and ensilage methods are suitable to be introduced as small - scale industry to coastal communities in Sri Lanka. Influence of natural antioxidants ie., tamarind (Tamarindus indica), garcinia (Garcinia cambogia) and bilin (Averrhoa bilimbi) and butylatedhydroxy toluene (BHT) on quality of liver oil extracted by ensilage and steam rendering methods was studied. The results showed the possibility of obtaining high quality liver oil using bilin (Averrhoa 
bilimbi) juice during the extraction of oil by ensilage method and butylated hydroxy toluene (BHT) (200 ppm) in steam rendering extraction procedures.

Shark liver oil was treated with ethanolic extracts of turmeric (rhizome of Curcuma domestica), tamarind (fruit and seeds of Tamarindus indica) and synthetic antioxidants (BHT and ascorbic acid) to determine the effectiveness of treatments as antioxidants. Turmeric (Curcuma domestica) turned out to be the most effective. A level of less than $250 \mathrm{ppm}$ of ethanolic extract of turmeric (Curcuma domestica) was sufficient to prevent oil oxidation and comparable to $200 \mathrm{ppm}$ of BHT. 